Working title: The developmental trajectory of open-mindedness: from 18 to 87 -years of age.

Authors: Daniel R. Edgcumbe Ph.D.

Affiliations: Department of Health and Behavioural Sciences, Newman University, Birmingham, United Kingdom

\title{
Important Note
}

This is a PrePrint Version of this manuscript. As such at the time of uploading this preprint this has not been peer-reviewed. 


\begin{abstract}
Objectives: The present study examined the role of aging in participants between 18 and 87years of age on open-mindedness in the Actively Open-minded Thinking (AOT) scale and the Actively Open-minded Thinking about Evidence (AOT-E) scale.

Method: The amalgamated data from 12 Amazon Mechanical Turk ${ }^{\mathrm{TM}}$ studies was analysed. This included a total of 9010 participants (age: $M=37.30, S D=14.13$ / sex: 4191 males, 4734 females and 85 who did not wish to state their sex). All participants completed the 7-item Actively Open-minded Thinking (AOT) scale, of these participants four-hundred and ninetyone also completed the 8-item Actively Open-minded Thinking about Evidence (AOT-E) scale (age: $\mathrm{M}=33.27, \mathrm{SD}=5.78 /$ sex: 2317 males, 2512 females and 62 who did not wish to state their sex).
\end{abstract}

Results: AOT score positively correlated with AOT-E score $(r=0.27)$. Age negatively correlated with AOT score $(r=-0.11)$ and AOT-E score $(r=-0.13)$. There was a statistical difference in AOT score between the age ranges of participants (18-28, 29-38, 39-48, 49-58, 59-68 and 69-87 years of age). There was also a difference in AOT-E score between the age ranges of participants too.

Discussion: The results showed that open-mindedness as measured by the AOT and AOT-E decreased as a function of aging. In an aging population were more adults work into later age the decrease in open-mindedness could influence many areas of judgments of decision-making.

Keywords: thinking disposition, open-mindedness, cognition, aging 
From the mid- $20^{\text {th }}$ century life expectancy increased rapidly as education, health care and technology improved and advanced (Costa, 2005). For most babies born in the $21^{\text {st }}$ century life expectancies are projected to increase from approximately 80-years of age to around 100-years of age (Mata et al., 2011). These rising life expectancies will likely cause an increase in longer working lives with a greater need for decision-making under uncertainty (Peeters et al., 2008). As life expectancy continues to grow, more decisions need to be made into older age, including decisions regarding finance (e.g., which mortgage or pension to choose), medical treatments (e.g., which medical treatment to choose) and politics (e.g., which party to vote for).

An active aging population will be influenced by age-related changes in healthy brain (Berry et al., 2018) and developmental changes in decision-making strategies (McGillivray et al., 2012). As the healthy brain ages there are naturally occurring atrophic changes to the prefrontal cortex (Cabeza, 2001) and dopamine system (Bäckman et al., 2006). Since the prefrontal cortex has a functional role in the cognitive functions that are associated with decision-making, for example, executive functions (EFs) (Funahashi \& Andreau, 2013) and working-memory (WM) (Curtis \& D'Esposito, 2003), it is reasonable that these changes would impact all areas of decision-making. For the healthy aging brain, cognitive processes that are reliant on the dorsolateral prefrontal cortex (DLPFC) region and orbitofrontal cortex regions (OFC) (e.g., EFs and WM) are negatively affected during aging (Levine et al., 1997; Lamar \& Resnick, 2004). Conversely, processes that are reliant on the ventromedial prefrontal cortex (vmPFC) region (e.g., emotional regulation (MacPherson et al., 2002)) are impacted by atrophy to a lesser extent. Moreover, other age-related changes in the healthy brain influence the dopaminergic system (Shohamy \& Adcock, 2010). Since dopamine is associated with many of the cognitive processes that are involved in decision-making, for example, reinforcement learning (Kim et al., 2012) and WM (D’Ardenne et al., 2012), it is expected that changes at this level would impact decision making. Importantly, as an individual ages there are 
systematic losses of dopamine-producing neurons in the substantia nigra (Gantz et al., 2018) and dopamine receptors (Karrer et al., 2017). Neuroimaging studies reliably find evidence for the changes in the dopaminergic system in the healthy brain (Bäckman et al., 2011; Karrer et al., 2017). The extent of any atrophy and reduction in dopamine vary considerably across healthy adults (Akiyama et al., 1997; Karrer et al., 2017). As the functionality of the dopamine systems decline at substantially different rates across individuals it follows that the associated cognitive processes would also deteriorate at different rates.

Intraindividual and interindividual variability in the cognitive processes for the aging individual influences all associated domains of decision-making (McGillivray et al., 2012; Wiesiolek et al., 2014). For instance, Beitz and colleagues (2014) found age-related changes in decision-making performance for the Iowa Gambling Task (IGT), in participants between the ages of 5 and 89-years of age. The older adults in their study exhibited performance deficits on the IGT compared to younger participants. The authors suggested that age-related cognitive changes as a function of intraindividual and interindividual variability resulted in the poorer performance in older adults. Moreover, age-related differences in reasoning and decisionmaking has also been reported in novel gambling tasks (Denburg \& Bechara, 2005). Denburg and Bechara (2005) examined interindividual variability in an attempt to explain their findings that a subset of the older adults in their study (aged 56 to 85) manifested impairments in their gambling task compared to the younger adults (aged 26 to 55). Although all participants in the study were neurologically healthy interindividual variability in education and gender could not explain their results. Denburg and Bechara concluded that disproportionate aging of the vmPFC across participants may explain the deficits in reasoning and decision-making.

The age-related change in cognition can be explained by considering the thinking disposition literature (Epstein et al., 1996; Haran et al., 2013). Thinking dispositions posit that we all have a tendency toward particular recognisable patterns of thinking that can underpin our decision- 
making outcomes. One such thinking disposition is 'open-mindedness' (Baron, 1993; Haran et al., 2013). At its most basic level the concept of open-mindedness proposes that some people are 'open-minded' whilst others are 'closed-minded'. An open-minded person is willing to consider information that contradicts with their personally held beliefs, whilst a closed-minded person would dismiss this information without any consideration of its content. The origin of open-mindedness in the psychology literature comes from the early work of Baron (1993) who sought to examine what the central principles of 'good thinking' in decision-making are. In this work, Baron (1993) found that attempting to view an issue from a multitude of perspectives (rather than just one perspective alone) predicted the avoidance of the myside bias (also called the confirmation bias) during 'good thinking'. Importantly, individuals who did not consider an issue from a multitude of perspectives used the myside bias by seeking to confirm the own beliefs when reading information about the issue.

Consequently, open-mindedness has often been used as a proxy for rational thinking when operationalised in the Actively Open-minded Thinking (AOT) scale (Toplak et al., 2011; Haran et al., 2013). Performance on the AOT correlates positively with reflective thinking (Toplak et al., 2011), crystalized intelligence (Toplak et al., 2014) and syllogistic reasoning (Toplak et al., 2014). It also consistently correlates negatively with religiosity (Pennycook et al., 2014), beliefs in conspiracy theories (Swami et al., 2014) and superstitious thinking (Toplak et al., 2014). Although the original form of the AOT consisted of 41-items (Stanovich \& West, 1997, 2007) a revised version of the AOT contains 7-items (Haran et al., 2013). In this paper, the short-form, 7-item version of the AOT was administered across all 12 studies. The data from these 12 studies were amalgamated into a single dataset.

Although the AOT has its merits in that it is a good predictor of both 'good' and 'bad' thinking, in recent years there has been questions about whether AOT is a unitary phenomenon (Svedholm-Häkkinen \& Lindeman, 2018). Critics of the AOT argue that the AOT scale does 
not measure a single phenomenon (Svedholm-Häkkinen \& Lindeman, 2018). They note that since the items that are included in the AOT scale were drawn from a variety of scales that are said to measure flexible thinking, absolutism, categorical thinking, dogmatism, belief identification, counterfactual thinking, openness-ideas and openness-values the composite score (i.e., AOT score) actually describes these selected items (Svedholm-Häkkinen \& Lindeman, 2018). This resulting score assesses cognitive flexibility, the willingness to perspective-switch, epistemological absolutism, and resistance to belief change. Given the origins of the items that are included in the AOT scale it is feasible to assume that the AOT measures a multidimensional phenomenon. One such way in which the multiple dimensions of the AOT could be assessed is to consider the AOT as measuring three associated functions (Baron, 2019). The first function is as a measure of norms, or standards, for the evaluation of thinking. As a norm of evaluative thinking the open-minded thinker assesses whether a statement is socially permissible. The second function is as a set of evaluative thinking dispositions for considering other people's thinking. Here the open-minded thinker considers another person's ideas in comparison to their own views and perspectives. For the third function, the individual examines the trustworthiness of the sources that claim authority. Future research is needed to assess the exact functions of the AOT scale and whether the AOT is a multidimensional or unitary phenomenon. In this paper the AOT was used to examine the influence of aging on open-mindedness as measured by the AOT scale.

A second revision of the AOT called the actively open-minded thinking about experience (AOT-E) scale was used across five studies (Pennycook et al., 2019) in the amalgamated dataset in this paper. This revised version of the AOT was created by Pennycook and colleagues (2019) to examine the role of open-mindedness in the evaluation of evidence. In part this thinking about evidence can be mapped on to the third of Baron's (2019) functions, during which the thinker must evaluate the trustworthiness of the source of the evidence. Such thinking 
is crucial for the dismissal of counterfactual thinking about conspiracist ideation (Pennycook et al., 2019) and paranormal thinking (Pennycook et al., 2019). High performance on the AOTE correlates negatively with beliefs in conspiracy theories (Pennycook et al., 2019), religiosity (McPhetres \& Pennycook, 2019) paranormal thinking (Pennycook et al., 2019). The authors of the eight-item AOT-E sourced the items from existing scales that measure belief identification, openness-value, and dogmatism. From a multidimensional perspective it is reasonable to suggest that although the AOT-E measures open-minded thinking about evidence it also measures the factors that are assessed by the sourced items that were compiled in to create the AOT-E. As with the AOT scale the AOT-E scale was administered in to examine the influence of age of open-minded thinking about evidence.

The current paper addresses some of the previous limitations in literature by examining the role of aging in judgment and decision-making. In particular, the role of aging for open-mindedness and open-mindedness about evidence are examined. Firstly, this addresses one source of interindividual variability that is crucial to an aging population, namely aging. The role of aging on decision-making is often overlooked in the decision-making literature due to small sample sizes and access to participants. Here the amalgamation of data from twelve studies into a large dataset that consisted of nine hundred and ten participants addresses this issue. Secondly, any variation in performance across two particular types of decision-making are assessed - openmindedness as measured by the AOT scale (Haran et al., 2013) and open-mindedness about evidence as measured by the AOT-E scale (Pennycook et al., 2019). Importantly and crucially, this paper addresses whether judgment and decision-making changes as a function of age in population were important decisions are increasingly made into the later years of life. 


\section{Method}

\section{Participants}

The data for 9010 unique participants from across 12 Amazon Mechanical Turk ${ }^{\mathrm{TM}}$ studies was amalgamated. All data was collected from studies between 2019 and 2020. All participants reported no neurological or psychiatric problems and were between 18 and 87-years of age (4191 males, 4734 females and 85 who did not wish to state their sex). All participants completed the AOT, and 4891 participants (2317 males, 2512 females and 62 who did not wish to state their sex) completed the AOT-E only. Table 1 shows the participant demographics for individuals divided into the six age groups (18-28, 29-38, 39-48, 49-58, 59-68, and 69-87). The basis for selection of these different age groups is presented in the introduction.

\section{[Table 1 here]}

\section{Design and Procedures}

This paper represents the amalgamation of data from twelve-studies. All experiments were conducted online through Amazon Mechanical Turk ${ }^{\mathrm{TM}}$. The scales included in this paper were counterbalanced within the individual studies to avoid potential carry over effects. These studies were administered online for about 30 minutes each.

\section{Measures}

Actively Open-minded Thinking (AOT) scale. The short-form 7-item AOT (Haran et al., 2013) was administered to measure an operationalised version of the concept of 'openmindedness'. This concept was originally conceived by Baron (1993) as a single principle that defines the propensity to engage in good thinking from a multitude of perspectives. This scale consists of 7 short statements to which a participant replies on a Likert scale from 1 (completely disagree) to 7 (completely agree). There is a maximum score of forty-nine for this scale with 
high scores denoting high open-mindedness and low scores suggesting closed-mindedness. For example...

People should take into consideration evidence that goes against conclusions they favour.

Actively Open-minded Thinking about Evidence (AOT-E) scale. The actively open-minded thinking about evidence (AOT-E) scale was administered to measure the concept of "metabeliefs" that should change as a consequence of the assimilation and consideration of new contradictory evidence (Pennycook et al., 2019). This scale focuses on one specific aspect of the AOT scale (Haran et al., 2013), that being that our thinking should change in response to evidenced beliefs, value and opinions that contract with our own. This scale consists of 8 short statements to which the participant replies on a Likert scale from 1 (I strongly disagree) to 6 (I strongly agree). There is a maximum score of fifty-three for this scale with high scores denoting high open-mindedness for evidence and low scores suggesting closed-mindedness for evidence. For example...

It is possible for someone to convince me to change my mind.

\section{Results}

A check of the correlations revealed that AOT score positively correlated with AOT-E score $(\mathrm{r}=0.27, p<0.01)$. Age negatively correlated with AOT score $(\mathrm{r}=-0.11, p<0.01)$ and AOT-E score $(\mathrm{r}=-0.13, p<0.01)$.

A one-way analysis of variance (ANOVA) was conducted to examine the effect of age on actively open-minded thinking, as measured by the AOT scale. Dependent variable was AOT score. Between-subject factors were age ranges (18-28, 29-38, 39-48, 49-58, 59-68 and 69-87). Normality checks and Levene's test were carried out and the assumptions met. There was a significant difference in AOT score, $\mathrm{F}(5,9004)=25.64, p<0.01, \eta_{\mathrm{p}}{ }^{2}=0.01$ between age ranges (Figure 1). Post-hoc comparisons using Tukey test were carried out. There were significant 
differences in open-mindedness between 18 to 28 year olds $(M=35.20, S E=0.12)$ and 29 to 38 -year olds $(\mathrm{M}=34.64, \mathrm{SE}=0.14), p=0.03,95 \% \mathrm{CI}[0.02,1.10] ; 39$ to 48 -year olds $(\mathrm{M}=$ 34.43, $\mathrm{SE}=0.20), p=0.01,95 \% \mathrm{CI}[0.10,1.44] ; 49$ to 58 -year olds $(\mathrm{M}=33.34, \mathrm{SE}=0.20), p$ $<0.01,95 \%$ CI [1.20, 2.53]; 59 to 68 -year olds $(\mathrm{M}=33.01, \mathrm{SE}=0.25), p<0.01,95 \% \mathrm{CI}[1.38$, 3.00]; and 69 to 87 -year olds $(\mathrm{M}=31.70, \mathrm{SE}=0.51), p<0.01,95 \% \mathrm{CI}[1.96,5.05]$. There were significant differences in open-mindedness between the 29 to 39 -year olds and 49 to 58 year olds, $p<0.01,95 \%$ CI $[0.61,2.00]$; 59 to 68 -year olds, $p<0.01,95 \%$ CI $[0.80,2.46]$; and 69 to 87 -year olds, $p<0.01,95 \%$ CI $[1.40,4.50]$. There were significant differences in openmindedness between 39 to 48 -year olds and 49 to 58 -year olds, $p=0.01,95 \%$ CI $[0.30,1.90]$; 59 to 68 -year olds, $p=<0.01,95 \%$ CI [0.50, 2.34]; and the 69 to 87 -year olds, $p<0.01,95 \%$ CI $[1.13,4.34]$. There was also significant difference in open-mindedness between the 49 to 58 -year olds and 69 to 87 -year olds, $p=0.04,95 \%$ CI $[0.03,3.25]$. There were no significant differences in open-mindedness between the 29 to 39 -year and 39 to 48 -year olds, $p=0.95$, $95 \%$ CI [-0.48, 0.91]; between the 49 to 58 -year olds and 59 to 68 -year olds, $p=0.91,95 \%$ CI $[-0.60,1.25]$; and between the 59 to 68 -year olds and 69 to 87 -year olds, $p=0.22,95 \%$ CI [$0.36,3.00]$.

[Figure 1 here] 


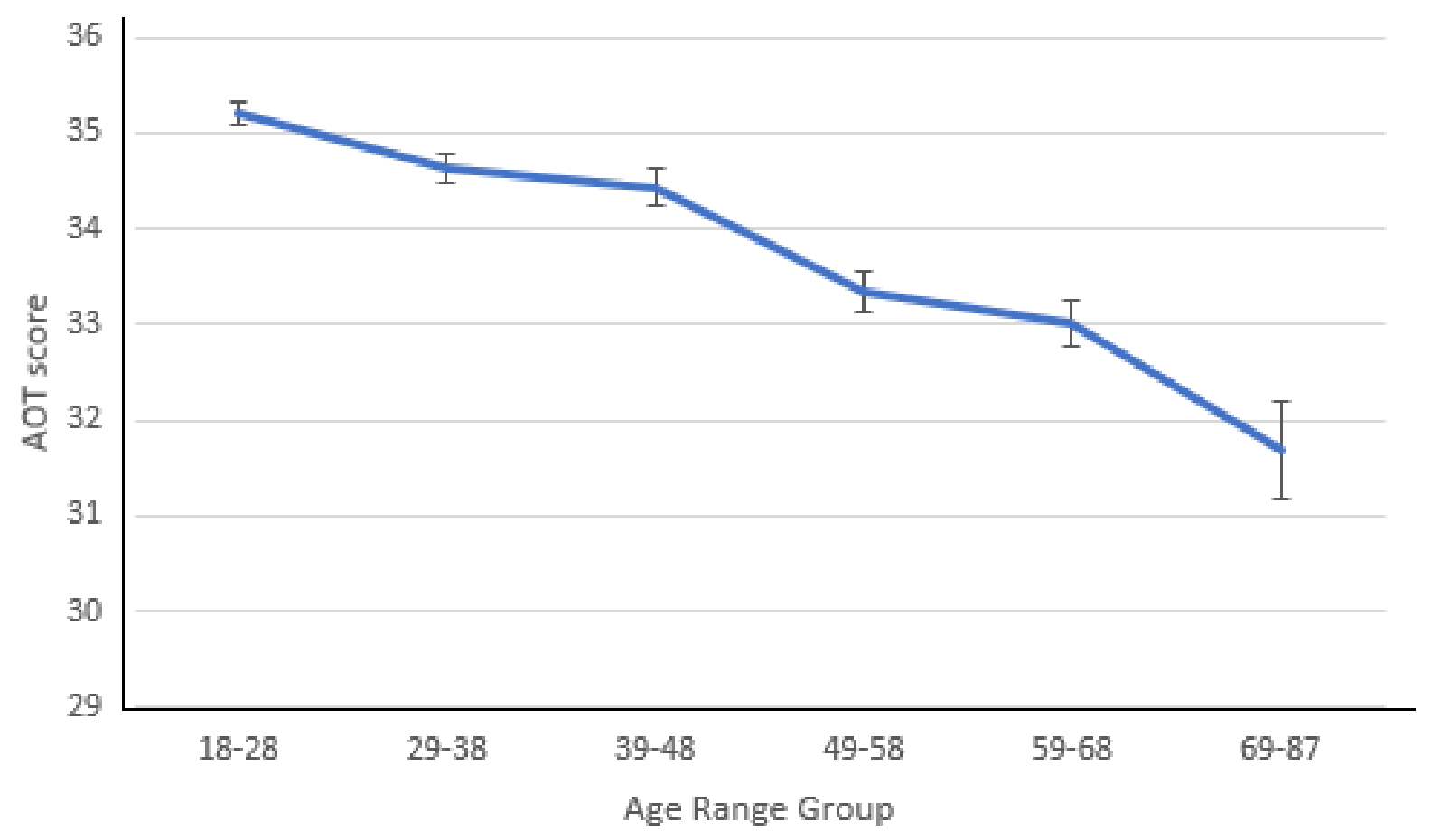

Figure 1. AOT score by age range group.

The second one-way ANOVA examined the effect of age on actively open-minded experience, as measured by the AOT-E. Dependent variable was AOT-E score. Between-subject factors were age ranges $(18-28,29-38,39-48,49-58,59-68$ and 69-87). Normality checks and Levene's test were carried out and the assumptions met. There was a significant difference in AOT-E score, $\mathrm{F}(5,4885)=22.81, p<0.01, \eta_{\mathrm{p}}{ }^{2}=0.02$ between age ranges (Figure 2 ). Post-hoc comparisons using Tukey test were carried out. There were significant differences in openmindedness for experience between 18 to 28 -year olds $(\mathrm{M}=33.92, \mathrm{SE}=0.15)$ and 49 to 58 year olds $(\mathrm{M}=32.22, \mathrm{SE}=0.17), p<0.01,95 \% \mathrm{CI}[1.01,2.40] ; 59$ to 68 -year olds $(\mathrm{M}=$ 32.12, $\mathrm{SE}=0.20), p<0.01,95 \% \mathrm{CI}[1.03,2.60]$; and 69 to 87 -year olds $(\mathrm{M}=31.38, \mathrm{SE}=0.43)$, $p<0.01,95 \%$ CI $[1.15,3.93]$. There were significant differences in open-mindedness for experience between 29 to 38-year olds $(\mathrm{M}=33.85, \mathrm{SE}=0.18)$ and 49 to 58 -year olds, $p<0.01$, 95\% CI [0.91, 2.36]; 59 to 68-year olds, $p<0.01,95 \%$ CI [0.93, 2.55]; and 69 to 87-year olds, 
$p<0.01,95 \%$ CI $[1.07,3.88]$. There were significant differences in open-mindedness for experience between 39 to 48 -year olds $(\mathrm{M}=34.00, \mathrm{SE}=0.23)$ and 49 to 58 -year olds, $p<0.01$, 95\% CI [0.91, 2.36]; 59 to 68-year olds, $p<0.01,95 \%$ CI [0.95, 2.78]; and 69 to 87-year olds, $p<0.01,95 \%$ CI $[1.13,4.08]$. There were no significant differences in open-mindedness of experience between the 18 to 28 -year olds and 29 to 38 -year olds, $p>1,95 \%$ CI $[-0.60,0.72]$; between the 18 to 28 -year olds and 39 to 48 -year olds, $p<0.01,95 \%$ CI [-0.85, 0.71]; between the 29 to 38 -year olds and 39 to 48 -year olds, $p>1,95 \%$ CI $[-0.94,0.70]$; between the 49 to 58 -year olds and 59 to 68 -year olds, $p>1,95 \%$ CI [-0.73, 0.94]; between the 49 to 58-year olds and 69 to 87 -year olds, $p=0.54,95 \%$ CI [-0.60, 2,26]; and between the 59 to 68 -year olds and 69 to 87 -year olds, $p=0.71,95 \%$ CI $[-0.73,2.21]$.

[Figure 2 here]

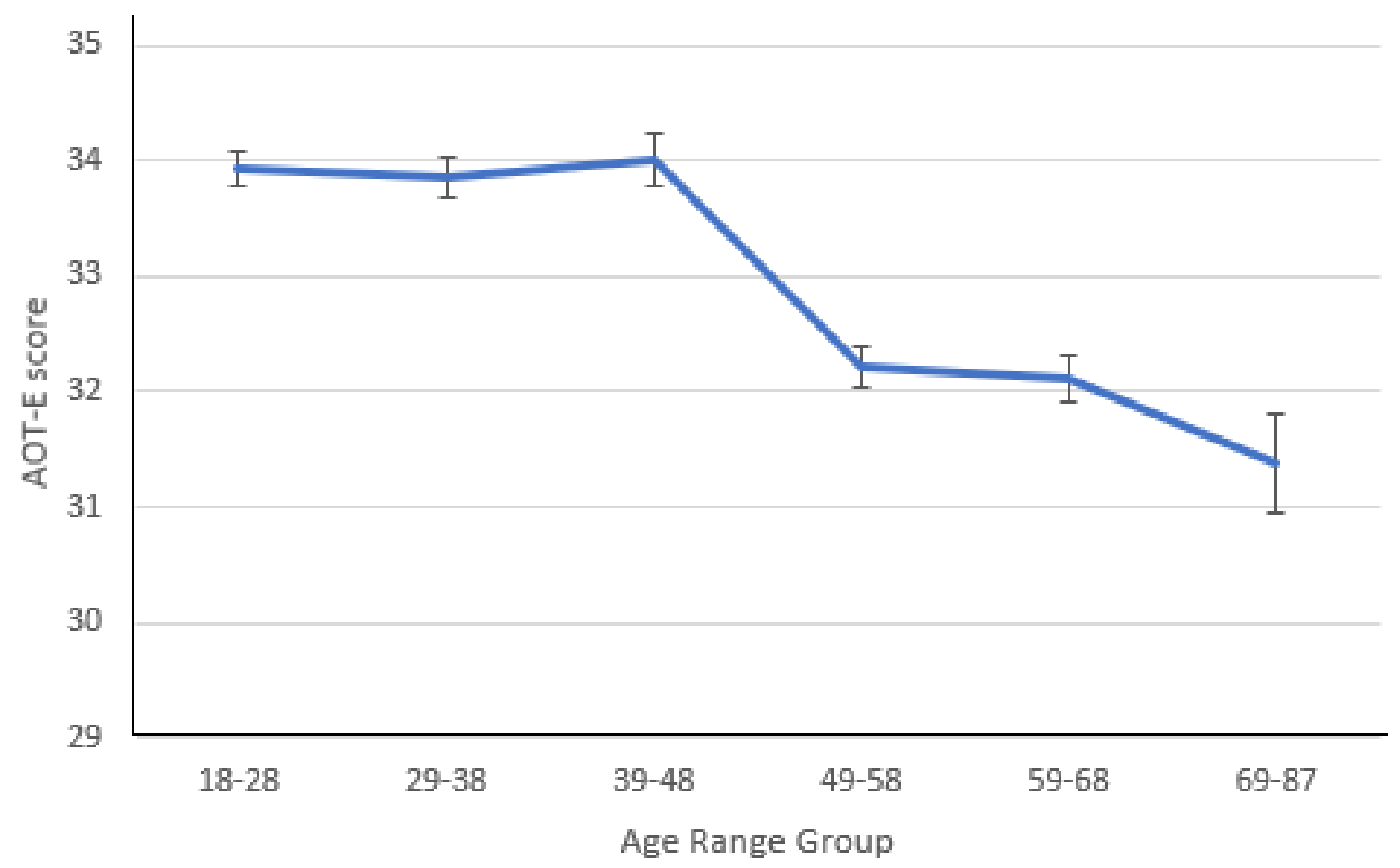

Figure 2. AOT-E score by age range group. 


\section{Discussion}

The present study examined the role of aging on open-mindedness for judgment and decisionmaking in a large dataset of participants. The results suggest that open-mindedness as measured by the AOT and AOT-E scales (Haran et al., 2013; Pennycook et al., 2019) change as a function of aging. Performance on measures of open-mindedness and open-mindedness about experience both decreased in a linear manner as age increases. These results were supported by strong negative correlations between age and AOT performance, and age and AOT-E performance. Whereas AOT performance and AOT-E performance positively correlated.

\section{The Role of Aging on the Healthy Brain}

The central focus of this paper was to examine the contribution of the aging brain on openmindedness in healthy participants. The results suggest that performance on measures of openmindedness decreases as individuals age. On average older adults had lower performance scores on both measures of open-mindedness compared to younger adults. These findings are in line with previous studies that report a decline in risk-taking propensity (Mamerow et al., 2016) and executive functioning (e.g., set-shifting in the Wisconsin Card Sorting Task) (MacPherson et al., 2002) as a function of aging. As risk-taking propensity (Weafer et al., 2013), executive functioning (Toplak et al., 2014) and open-mindedness (Toplak et al., 2014) reliably correlate with each other in the literature it is likely that the changes in these processes are driven by changes in the related underlying neurophysiology (Alvarez \& Emory, 2006; Lara \& Wallis, 2015). These processes are all associated with activation in the prefrontal cortex, specifically the DLPFC (Rypma \& D’Esposito, 1999; Alvarez \& Emory, 2006).

The prefrontal theories of cognitive aging can explain why there is a decrease in openmindedness as the healthy brain ages (McGillivray et al., 2012; Mather, 2016). The prefrontal regions are more susceptible to age-related atrophic changes than other regions of the healthy 
brain (Gunning-Dixon et al., 2009). In particular, although there are atrophic changes in all areas of the prefrontal regions, for example, as in the OFC and vmPFC this decrease in brain volume is more pronounced in the DLPFC (Mather, 2016). The findings from Fjell and colleagues (2009) support the rates of decline across the prefrontal cortex. In a Magnetic Resonance Imaging (MRI) study Fjell and colleagues (2009) aggregated a large sample of eight hundred and three participants from across 6 different smaller samples. The age of the participants in their samples ranged from 18 to 94 -years of age. The comparative rates of decline for prefrontal region brain volume revealed that the DLPFC significantly declined in volume more than any other prefrontal region.

Subsequent findings that performance on tasks reliant on DLPFC function (e.g., EFs \& WM) decline at a greater rate than tasks reliant on vmPFC performance (e.g., social conduct regulation and emotional processing) provide a compelling case for the role of the DLPFC in the reduction of open-mindedness in older adults (McGillivray et al., 2012; Tranel et al., 2002). In particular, tasks associated with the DLPFC such as EF (MacPherson et al., 2002) and WM (Balconi, 2013) seem to be most negatively affected by normal aging (McGillivray et al., 2012). Whereas tasks linked to activation in the vmPFC such as social behavioural regulation and affective processing are affected to a lesser extent (MacPherson et al., 2002; Tranel et al., 2002).

\section{The Role of Aging on Cognition}

A number of theories have been proposed in attempts to explain the change in cognition as a function of aging (McGillivray et al., 2012; West, 1996). Each of these theories focus on possible mechanisms for driving age-related change in cognition during healthy aging. As health care improves and the retirement age increases it is increasingly important to consider these theories when individuals are working into older age (Peeters et al., 2008). 
The first of these theories, the general slowing theory posits that there is a reduction in the speed of cognitive processing as the individual ages (Eusop et al., 2001; Verhaegen \& Poncelet, 2013). The increased latency for these cognitive processes account for the age-related decline in cognitive performance when scores are compared between older adults and younger adults (Verhaegen \& Poncelet, 2013). For example, in object naming tasks participants in their 50s show slower naming latencies compared to younger persons, and participants in their 60s and 70s show further increases in latencies and decreases in accuracy (Verhaegen \& Poncelet, 2013). Accordingly, the reduced speed in cognitive processing is thought to result from the slowing of cognitive language processes that are crucial for the understanding of most cognitive tasks (Verhaegen \& Poncelet, 2013). As language processing latencies increase the time needed to perform these cognitive operations become restricted. Therein if a task or judgment requires the use of competing responses, as in the AOT (Haran et al., 2013) were an individual must consider opposing views on a statement some of these responses may be lost by the time of the completed processing. Crucially, this could go part way to explaining some of the reduction in AOT (Haran et al., 2013) and AOT-E (Pennycook et al., 2019) performance in older participants compared to the younger participants in this paper. However, the question of whether cognitive slowing remains constraint across all cognitive tasks remains controversial and unclear.

The second cognitive theory of aging on cognition is the reduced resource theory which proposes that the decline in cognitive performance results from the reduced accessibility and availability to the allocation of attentional resources (Hartley \& Little, 1999). Such attentional resources are necessary for the efficient performance of cognitive tasks (Hartley \& Little, 1999; McGillivray et al., 2012). For example, when an individual is required to divide their attention between multiple stimuli there is a detrimental impact on the processing of both stimuli. Accordingly, as an individual ages their capacity to allocate attentional resources decreases to 
the extent that the reduction in available attentional resources make it difficult for an older adult to engage in cognitively demanding tasks (McGillivray et al., 2012). Importantly, this could also in part explain the reduction in open-mindedness as a result of aging. If older participants have less access to attentional resources then they will not be able to hold opposing views on a particular statement in mind whilst evaluating and preparing a response. The inability to evaluate opposing view would result in deceased open-mindedness as measured by the AOT (Haran et al., 2013) and AOT-E (Pennycook et al., 2019) compared to younger participants.

\section{Open-mindedness and Aging}

The decrease in open-mindedness and open-mindedness about evidence as a function of aging in the large sample of 9010 participants in this paper provide evidence for the detrimental impact of aging on open-mindedness. As scores for the AOT scale (Haran et al., 2013) and the AOT-E scale (Pennycook et al., 2019) decline from younger participants to older participants it is expected that this result is driven by age-related change in the healthy brain (MacPherson et al., 2002) and associated cognitive functions (McGillivray et al., 2012). Since rational judgments, decisions and actions require open-mindedness (Toplak et al., 2011; 2014) it is crucial that the interindividual variability in these processes be examined in future research.

Importantly, lower levels of open-mindedness in older adults compared to younger persons can be explained by the findings in the psychology literature (Kokis et al., 2002). Older age is associated with high levels of superstitious thinking (Kokis et al., 2002; Toplak et al., 2011) and religiosity (Pennycook et al., 2012) - both factors that are lower in thinkers who are younger and who value evidence over personal feeling. Each of these cognitive factors are in turn associated with low scores on measures of open-mindedness (Kokis et al., 2002; Svedholm-Häkkinen \& Lindeman, 2018; Toplak et al., 2011). Crucially, although some studies 
report positive correlations between age and open-mindedness a closer inspection of the age range of participants can explain these results (Haran et al., 2013). For example, where Haran et al., (2013) report a positive correlation of $r=0.21$ their mean average age range of participants was 35.28-years of age. This is likely the case for most studies for which the authors do not explicitly aim to examine a large age range of participants. By specifically recruiting participants with a large age range, as in this paper, with participants from 18 to 87 years of age an accurate representation of the developmental trajectory of open-mindedness can be achieved.

An important caveat is that although aging and open-mindedness reliably correlate positively with each other in the literature (Haran et al., 2013; Toplak et al., 2014) and here other factors can influence the association between aging and open-mindedness (Baron, 2019). For example, the formal education level of the thinker can impact how open-minded the thinker is (Baron, 1993; 2019; Haran et al., 2013). Other factors that can influence the interaction between age and open-mindedness may include intelligence (Toplak et al., 2011), expertise (Baron, 1993), scepticism (Pennycook et al., 2019), and political ideology (Pennycook et al., 2019).

\section{Implications and Limitations}

The current study has some practical implications for judgment and decision-making in older age. This has particular implications for an aging population in which a greater number of adults choose to work at an age in which they would traditionally retire. These decisions that could be influenced by this age-related reduction in open-mindedness compared to younger peers could include, but are not limited to financial decisions (e.g., mortgage and retirement plans), medical decisions (e.g., to accept a medical treatment or not), legal decisions (e.g., to pursue legal proceedings or not) and political decisions (e.g., to vote for one candidate or party or not). Interventions to protect against 'closed-minded' decision-making could include 
training thinkers about how their beliefs can impact decision-making and introducing these thinkers to people with other views and perspectives on an event or topic (e.g., to 'leave' or 'remain' in the Brexit vote). A discussion with individuals who have opposing views could cause the thinker to re-evaluate their own views, perspectives and decisions on a topic. For instance, by trying to understand how other thinkers form their own decisions the thinker may choose to view the topic from multiple perspectives and become more open-minded. As they become more open-minded, they could opt to make a different decision about which way to vote.

These results should be considered alongside the limitations and implications of this research. Firstly, the participants in this paper were all computer literate. A replication study may find that individuals who are not computer literate may choose to be more or less open-minded. Secondly, the data collection for this paper included participants across the Amazon Mechanical Turk participation pool, replications should aim to collect further data from a wider source of participants.

In summary, this study extends the previous research on open-mindedness by examining the impact of aging on judgment and decision-making in a large amalgamated dataset. The agerelated decline in open-mindedness was evident for both the AOT and AOT-E scales. These results suggest that it is important to consider why a thinker makes a decision when important judgments and decisions are made into later age. 


\section{References}

Akiyama, H., Meyer, J. S., Mortel, K. F., Terayama, Y., Thornby, J. I., \& Konno, S. (1997). Normal human aging: Factors contributing to cerebral atrophy. Journal of the Neurological Sciences, 152(1), 39-49. doi:10/1016/Soo22-510X(97)00141-X

Alvarez, J. A., \& Emory, E. (2006). Executive function and the frontal lobes: A meta-analytic review. Neuropsychology Review, 16(1), 17-42. doi: 10.1007/s11065-006-9002-x

Bäckman, L., Karlsson, S., Fischer, H., Karlsson, P., Brehmer, Y., Rieckmann, A., MacDonald, S. W., Farde, L., \& Nyberg, L. (2011). Dopamine D1 receptors and age differences in brain activation during working memory. Neurobiology of Aging, 32(10), 1849-1856. doi: 10.1016/j.neurobiolaging.2009.10.018

Bäckman, L., Nyberg, L., Lindenberger, U., Li, S. C., \& Farde, L. (2006). The correlative triad among aging, dopamine, and cognition: Current status and future prospects. Neuroscience \& Biobehavioral Reviews, 30(6), 791-807. doi: 10.1016/j.neubiorev.2006.06.005

Balconi, M. (2013). Dorsolateral prefrontal cortex, working memory and episodic memory processes: Insight through transcranial magnetic stimulation techniques. Neuroscience Bulletin, 29(3), 381-389. doi: 10.1007\%2Fs12264-013-1309-z

Baron, J. (1993). Why Teach Thinking?-An Essay. Applied Psychology, 42(3), 191-214. Retrieved from https://www.sas.upenn.edu/ baron/papers/whyteachthinking.pdf Baron, J. (2019). Actively open-minded thinking in politics. Cognition, 188, 8-18. doi: 10.1016/j.cognition.2018.10.004

Beitz, K. M., Salthouse, T. A., \& Davis, H. P. (2014). Performance on the Iowa Gambling Task: From 5 to 89 years of age. Journal of Experimental Psychology: General, 143(4), 1677-1689. doi: 10.1037/a0035823 
Berry, A. S., Jagust, W. J., \& Hsu, M. (2018). Age-related variability in decision-making: Insights from neurochemistry. 19(1), 415-434. doi: 10.3758/s13415-018-00678-9

Cabeza, R. (2001). Cognitive neuroscience of aging: Contributions of functional neuroimaging. Scandinavian Journal of Psychology, 42(3), 277-286. doi: $10.1111 / 1467-9450.00237$

Costa, D. L. (2005). Causes of improving health and longevity at older ages: A review of the explanations. Genus, 61(1), 21-38. Retrieved from https//www.jstor.org/stable/29788834

Curtis, C. E., \& D'Esposito, M. (2003). Persistent activity in the prefrontal cortex during working memory. Trends in Cognitive Sciences, 7(9), 415-423. doi: 10.1016/S13646613(03)00197-9

D’Ardenne, K., Eshel, N., Luka, J., Lenartowicz, A., Nystrom, L. E., \& Cohen, J. D. (2012). Role of prefrontal cortex and the midbrain dopamine system in working memory updating. Proceedings of the National Academy of Sciences, 109(49), 19900-19909. doi: 10.1073/pnas.1116727109

Denburg, N. L., Tranel, D., \& Bechara, A. (2005). The ability to decide advantageously declines prematurely in some normal older persons. Neuropsychologia, 43(7), 10991106. doi: 10.1016/j.neuropsychologia.2004.09.012

Epstein, S., Pacini, R., Denes-Raj, V., \& Heier, H. (1996). Individual differences in intuitiveexperiential and analytical-rational thinking styles. Journal of Personality and Social Psychology, 71(2), 390-407. doi: 10.1037/0022-3514.71.2.390

Eusop, E., Sebban, C., \& Piette, F. (2001). Aging and cognitive slowing: Example of attentional processes-evaluation procedures and related questions. L'Encephale, 27(1), 39-44. doi: 11294037 
Fjell, A. M., Westlye, L. T., Amlien, I., Espeseth, T., Reinvang, I., Raz, N., Agartz, I., Salat, D. H., Greve, D. N., \& Fischl, B. (2009). High consistency of regional cortical thinning in aging across multiple samples. Cerebral Cortex, 19(9), 2001-2012. doi: 10.1093/cercor/bhn232

Funahashi, S., \& Andreau, J. M. (2013). Prefrontal cortex and neural mechanisms of executive function. Journal of Physiology-Paris, 107(6), 471-482. doi: 10.1016/j.jphysparis.2013.05.001

Gantz, S. C., Ford, C. P., Morikawa, H., \& Williams, J. T. (2018). The evolving understanding of dopamine neurons in the substantia nigra and ventral tegmental area. Annual Review of Physiology, 80, 219-241. doi: 10.1146/annurev=physiol-021317121615

Gunning-Dixon, F. M., Brickman, A. M., Cheng, J. C., \& Alexopoulos, G. S. (2009). Aging of cerebral white matter: A review of MRI findings. International Journal of Geriatric Psychiatry: A Journal of the Psychiatry of Late Life and Allied Sciences, 24(2), 109-117. doi: 10.1002/gps.2087

Haran, U., Ritov, I., \& Mellers, B. A. (2013). The role of actively open-minded thinking in information acquisition, accuracy, and calibration. Judgment and Decision Making, 8(3), 188-201. Retrieved from https://www.journal.sjdm.org/13/13124a/jdm13124a/jdm12124a.pdf

Hartley, A. A., \& Little, D. M. (1999). Age-related differences and similarities in dual-task interference. Journal of Experimental Psychology: General, 128(4), 416-449. doi: $10.1037 / 0096-3445.128 .4 .416$

Karrer, T. M., Josef, A. K., Mata, R., Morris, E. D., \& Samanez-Larkin, G. R. (2017). Reduced dopamine receptors and transporters but not synthesis capacity in normal 
aging adults: A meta-analysis. Neurobiology of Aging, 57, 36-46. doi: 10.1016/j.neurobiolaging.2017.05.006

Kim, K. M., Baratta, M. V., Yang, A., Lee, D., Boyden, E. S., \& Fiorillo, C. D. (2012). Optogenetic mimicry of the transient activation of dopamine neurons by natural reward is sufficient for operant reinforcement. PloS One, 7(4). doi: 10.1371/journal.pone.0033612

Kokis, J. V., Macpherson, R., Toplak, M. E., West, R. F., \& Stanovich, K. E. (2002). Heuristic and analytic processing: Age trends and associations with cognitive ability and cognitive styles. Journal of Experimental Child Psychology, 83(1), 26-52. doi: $10.1016 / \mathrm{S} 0022-0965(02) 00121-2$

Lamar, M., \& Resnick, S. M. (2004). Aging and prefrontal functions: Dissociating orbitofrontal and dorsolateral abilities. Neurobiology of Aging, 25(4), 553-558. doi: 10.1016/j.neurobiolaging.2003.06.005

Lara, A. H., \& Wallis, J. D. (2015). The role of prefrontal cortex in working memory: A mini review. Frontiers in Systems Neuroscience, 9, 173-180. doi: 10.3389/fnsys.2015.00173

Levine, B., Stuss, D. T., \& Milberg, W. P. (1997). Effects of aging on conditional associative learning: Process analyses and comparison with focal frontal lesions. Neuropsychology, 11(3), 367-381. doi: 10.1037/0894-4105.11.3.367

MacPherson, S. E., Phillips, L. H., \& Della Sala, S. (2002). Age, executive function and social decision making: A dorsolateral prefrontal theory of cognitive aging. Psychology and Aging, 17(4), 598-609. doi: 10.1037/0882-7974.17.4.598

Mamerow, L., Frey, R., \& Mata, R. (2016). Risk taking across the life span: A comparison of self-report and behavioral measures of risk taking. Psychology and Aging, 31(7), 711723. doi: $10.1037 / \mathrm{pag} 0000124$ 
Mata, R., Josef, A. K., Samanez-Larkin, G. R., \& Hertwig, R. (2011). Age differences in risky choice: A meta-analysis. Annals of the New York Academy of Sciences, 1235, 18-29. doi: 10.1111/j.1749-6632.2011.06200.x

Mather, M. (2016). The affective neuroscience of aging. Annual Review of Psychology, 67, 213-238. doi: 10.1146/annurev-psych-122414-033540

McGillivray, S., Friedman, M. C., \& Castel, A. D. (2012). Impact of aging on thinking. In The Oxford handbook of thinking and reasoning (pp. 560-582). Oxford University Press New York, NY.

McPhetres, J., \& Pennycook, G. (2019). Science beliefs, political ideology, and cognitive sophistication. PsyArXiv Working Paper, 1-33. Retrieved from https://doi.org/10.31219/OSF.IO/AD9V7

Peeters, M., van Emmerik, H., Kooij, D., de Lange, A., Jansen, P., \& Dikkers, J. (2008). Older workers' motivation to continue to work: Five meanings of age. Journal of Managerial Psychology. 23(4), 364-394. doi: 10.1108/02683940810869015

Pennycook, G., Cheyne, J. A., Barr, N., Koehler, D. J., \& Fugelsang, J. A. (2014). Cognitive style and religiosity: The role of conflict detection. Memory \& Cognition, 42(1), 1-10. doi: $10.3758 / \mathrm{s} 13421-013-0340-7$

Pennycook, G., Cheyne, J. A., Koehler, D., \& Fugelsang, J. A. (2019). On the belief that beliefs should change according to evidence: Implications for conspiratorial, moral, paranormal, political, religious, and science beliefs. PsyArXiv Working Paper, 1-69. Retrieved from https://doi.org/10.31234/OSF.IO/A7K96

Pennycook, G., Cheyne, J. A., Seli, P., Koehler, D. J., \& Fugelsang, J. A. (2012). Analytic cognitive style predicts religious and paranormal belief. Cognition, 123(3), 335-346. doi: 10.1016/j.cognition.2012.03.003 
Rypma, B., \& D’Esposito, M. (1999). The roles of prefrontal brain regions in components of working memory: Effects of memory load and individual differences. Proceedings of the National Academy of Sciences, 96(11), 6558-6563. Retrieved from https://www.jstor.org/stable/47910

Shohamy, D., \& Adcock, R. A. (2010). Dopamine and adaptive memory. Trends in Cognitive Sciences, 14(10), 464-472. doi: 10.1016/j.tics.2010.08.002

Stanovich, K. E., \& West, R. F. (1997). Reasoning independently of prior belief and individual differences in actively open-minded thinking. Journal of Educational Psychology, 89(2), 342. Retrieved from https://keithstanovich/site/research_on_reasoning_files/stanovich_JEP_1997.pdf

Stanovich, K. E., \& West, R. F. (2007). Natural myside bias is independent of cognitive ability. Thinking \& Reasoning, 13(3), 225-247. doi: 10.1080/13546780600780796

Svedholm-Häkkinen, A. M., \& Lindeman, M. (2018). Actively open-minded thinking: Development of a shortened scale and disentangling attitudes towards knowledge and people. Thinking \& Reasoning, 24(1), 21-40. doi: 10.1080/13546783.2017.1378723

Swami, V., Voracek, M., Stieger, S., Tran, U. S., \& Furnham, A. (2014). Analytic thinking reduces belief in conspiracy theories. Cognition, 133(3), 572-585. doi: 10.1016/j.cognition.2014.08.006

Toplak, M. E., West, R. F., \& Stanovich, K. E. (2011). The Cognitive Reflection Test as a predictor of performance on heuristics-and-biases tasks. Memory \& Cognition, 39(7), 1275-1283. doi: 10.3758/s13421-011-0104-1

Toplak, M. E., West, R. F., \& Stanovich, K. E. (2014). Rational thinking and cognitive sophistication: Development, cognitive abilities, and thinking dispositions. Developmental Psychology, 50(4), 1037-1048. doi: 10.1037/a0034910 
Tranel, D., Bechara, A., \& Denburg, N. L. (2002). Asymmetric functional roles of right and left ventromedial prefrontal cortices in social conduct, decision-making, and emotional processing. Cortex, 38(4), 589-612. doi: 10.1016/S0010-9452(08)70024-8

Verhaegen, C., \& Poncelet, M. (2013). Changes in naming and semantic abilities with aging from 50 to 90 years. Journal of the International Neuropsychological Society, 19(2), 119-126. doi: 10.1017/S1355617712001178

Weafer, J., Baggott, M. J., \& de Wit, H. (2013). Test-retest reliability of behavioral measures of impulsive choice, impulsive action, and inattention. Experimental and Clinical Psychopharmacology, 21(6), 475-481. doi: 10.1037/a0033659

West, R. L. (1996). An application of prefrontal cortex function theory to cognitive aging. Psychological Bulletin, 120(2), 272-292. doi: 10.1037/0033-2909.120.2.272

Wiesiolek, C. C., Foss, M. P., \& Diniz, P. R. B. (2014). Normal aging and decision-making: A systematic review of the literature of the last 10 years. Jornal Brasileiro de Psiquiatria, 63(3), 255-259. doi: 10.1590/0047-2085000000033 
Tables

Table 1.

\begin{tabular}{ccc}
\hline \multicolumn{3}{c}{ All studies* } \\
\hline Age range group & N (overall \%) & $\begin{array}{c}\text { \% male/female/do not wish to } \\
\text { state their sex }\end{array}$ \\
\hline $\mathbf{1 8 - 2 8}$ & $3124(34.7)$ & $46.20 / 52.50 / 1.20$ \\
$\mathbf{2 9 - 3 8}$ & $2448(27.2)$ & $46.20 / 53.20 / 0.50$ \\
$\mathbf{3 9 - 4 8}$ & $1250(13.9)$ & $41.60 / 57.50 / 0.90$ \\
$\mathbf{4 9 - 5 8}$ & $1246(13.8)$ & $47.80 / 51.20 / 1.00$ \\
$\mathbf{5 9 - 6 8}$ & $765(8.50)$ & $52.40 / 46.70 / 0.90$ \\
$\mathbf{6 9 - 8 7}$ & $177(2.00)$ & $55.40 / 42.90 / 1.70$ \\
\hline \multicolumn{4}{c}{ Age range group } & AOT only studies (without the AOT-E) $* *$ \\
\hline & N (overall \%) & \% male/female/do not wish to \\
state their sex \\
\hline $\mathbf{1 8 - 2 8}$ & $1698(41.20)$ & $46.70 / 52.40 / 0.90$ \\
$\mathbf{3 9 - 4 8}$ & $1352(32.80)$ & $47.10 / 52.40 / 0.40$ \\
$\mathbf{4 9 - 5 8}$ & $617(15.00)$ & $43.60 / 56.10 / 0.30$ \\
$\mathbf{5 9 - 6 8}$ & $306(7.40)$ & $35.30 / 64.70 / 0$ \\
$\mathbf{6 9 - 8 7}$ & $122(3.00)$ & $46.70 / 53.30 / 0$ \\
& $24(0.60)$ & $41.70 / 58.30 / 0$ \\
\hline
\end{tabular}

AOT-E \& AOT studies***

Age range group $\quad \mathrm{N}($ overall \%) $\%$ male/female/do not wish to state their sex

\begin{tabular}{ccc}
\hline $\mathbf{1 8 - 2 8}$ & $1426(29.20)$ & $45.70 / 52.70 / 0.40$ \\
$\mathbf{2 9 - 3 8}$ & $1096(22.40)$ & $45.20 / 54.20 / 0.60$ \\
$\mathbf{3 9 - 4 8}$ & $633(12.90)$ & $39.70 / 58.90 / 1.40$ \\
$\mathbf{4 9 - 5 8}$ & $940(19.20)$ & $51.90 / 46.80 / 1.30$ \\
$\mathbf{5 9 - 6 8}$ & $643(13.10)$ & $53.50 / 45.40 / 1.10$ \\
$\mathbf{6 9 - 8 7}$ & $153(3.10)$ & $57.50 / 40.50 / 2.00$ \\
\hline Notes: (*) across all 12 studies, $(* *)$ across 7 studies, (***) across 5 studies. Percentage by
\end{tabular}

Notes: $(*)$ across all 12 studies, $\left({ }^{* *}\right)$ across 7 studies, $(* * *)$ across 5 studies. Percentage by number of participants denote overall percentage across age groups. Percentage by sex/gender denote percentage within age group. 


\section{Table captions}

Table 1. Demographics for age range groups for the all 12 studies (all participants), the 7 AOT only studies (AOT only) and 5 AOT an AOT-E studies (AOT-E with AOT). 